\title{
Nitroso-Caged Rhodamine: A Superior Green Light Activatable Fluorophore for Single-Molecule Localization Super-Resolution Imaging
}

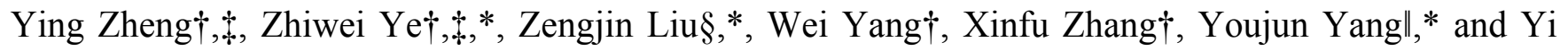
Xiao†,*

$\dagger$ State Key Laboratory of Fine Chemicals, Dalian University of Technology, Dalian 116024, China

$\S$ Drug research Center of Integrated Traditional Chinese and Western Medicine, Affiliated Traditional Chinese Medicine Hospital, Southwest Medical University, Luzhou 646000, China

" State Key Laboratory of Bioreactor Engineering, Shanghai Key Laboratory of Chemical Biology, School of Pharmacy, East China University of Science and Technology, Shanghai 200237, China

$\ddagger$ These authors contributed equally.

*xiaoyi@dlut.edu.cn (Y.Xiao)

* yezhiwei@dlut.edu.cn (Z. Ye)

* youjunyang@ecust.edu.cn (Y. Yang)

*zengjinliu@swmu.edu.cn (Z. Liu) 


\section{Table of Contents}

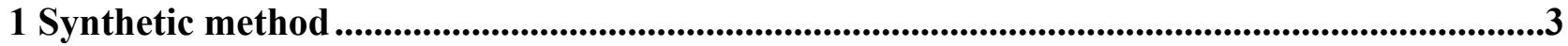

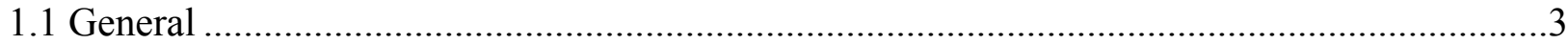

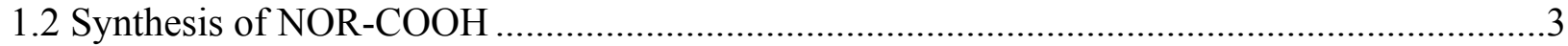

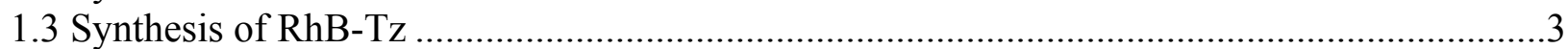

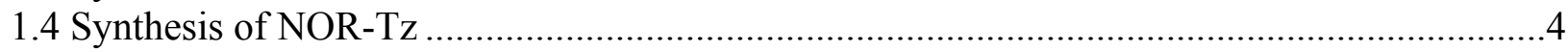

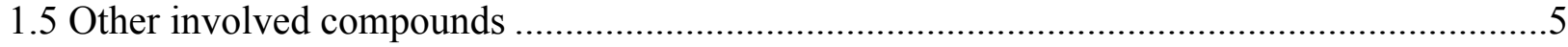

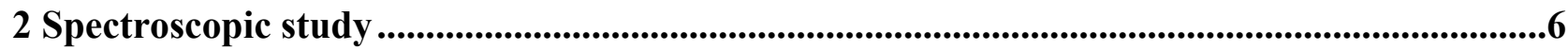

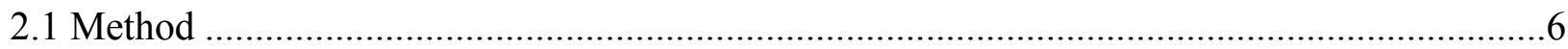

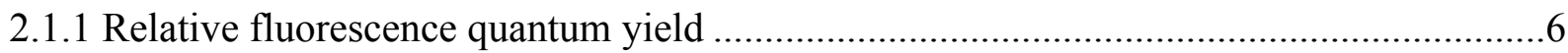

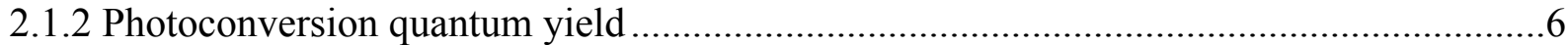

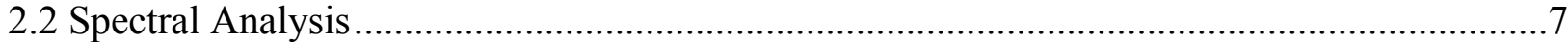

3 Single-molecule analysis .............................................................................................................10

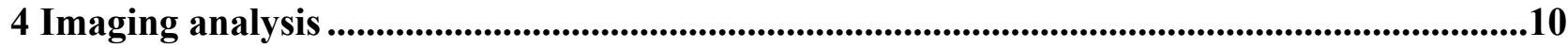

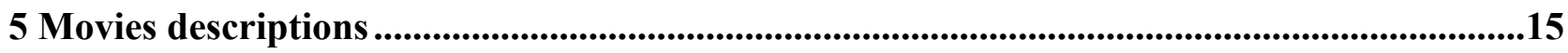

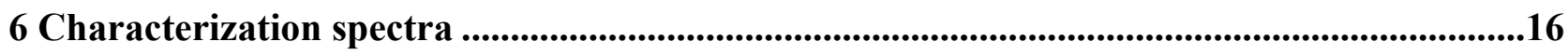

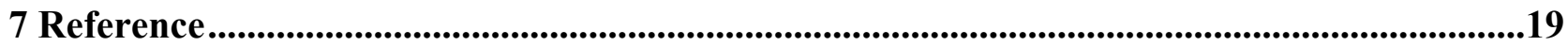




\section{Synthetic method}

\subsection{General}

All regents, e.g. $\mathrm{MeOH}, \mathrm{DMF}$, acetonitrile, triethylamine, etc., were purchased from commercial suppliers and used as received. Column chromatography was performed with silica gel (200-300 mesh and 300-400 mesh). High-performance liquid chromatography (HPLC) was run on Venus C18 $5 \mu \mathrm{m}$ column ( $\Phi 4.6 \mathrm{~mm}, 150 \mathrm{~mm}$ ) and Hypersil $\mathrm{SiO}_{2} 5 \mu \mathrm{m}$ column ( $\left.\Phi 4.6 \mathrm{~mm}, 200 \mathrm{~mm}\right)$ using Elite P230 equipped with a sample injection valve (Rheodyne models 7725i), and the products were detected at 254 $\mathrm{nm}$ with an Elite UV230-II detector. The normal flow rate was $0.8 \mathrm{~mL} / \mathrm{min}$ with mixtures of methanol and water (contained $0.1 \%$ acetic acid) as mobile phase. Preparative HPLC was run on Sinochrom ODSBP $10 \mu \mathrm{m}$ column ( $\Phi 30 \mathrm{~mm}, 250 \mathrm{~mm}$ ) and Hypersil $\mathrm{SiO}_{2} 10 \mu \mathrm{m}$ column ( $\left.\Phi 30 \mathrm{~mm}, 250 \mathrm{~mm}\right)$ using Elite P270 equipped with a sample injection valve (Rheodyne models 3325i), and the products were detected at $254 \mathrm{~nm}$ with an Elite UV230-II detector.

${ }^{1} \mathrm{H}$ NMR and ${ }^{13} \mathrm{C}$ NMR were measured on Bruker Avance II 400, Bruker AVANCE III 500 and Varian MERCURY 400 spectrometers. Mass spectra and high-resolution mass spectra were recorded on HP 1100 LC-MSD, gas chromatography/TOF Mass, thermo Scientific LTQ Orbitrap XL, Waters Synapt G2-Si HDMS and UPLC/Q-TOF Mass spectrometers.

\subsection{Synthesis of NOR-COOH}
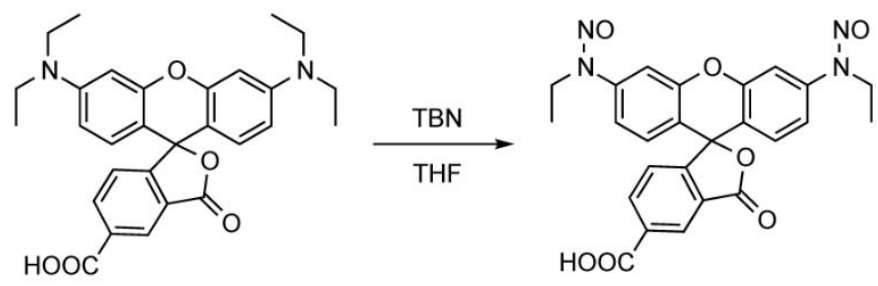

NOR-COOH

$\mathrm{RhB}-\mathrm{COOH}$ isomers $(50 \mathrm{mg}, 0.10 \mathrm{mmol})$ was dissolved in dry tetrahydrofuran $(5 \mathrm{~mL})$ and butyl nitrite $(122 \mathrm{uL}, 1.03 \mathrm{mmol})$ was added. The mixture was heated to $60{ }^{\circ} \mathrm{C}$ and stirred for $2 \mathrm{~h}$. After the completion of the reaction, solvent was removed under reduced pressure. The crude product was further purified through silica gel column chromatography with a mixture of dichloromethane and glacial acetic acid $(100 / 1, \mathrm{v} / \mathrm{v})$ as eluent. The crude product was further purified by preparative HPLC with a mixture of dichloromethane (contained 1\% glacial acetic acid), and ethyl acetate (97/3, v/v) as mobile phase. The collected solution was dried in vacuo to afford NOR-COOH (beige solid, $28 \mathrm{mg}$, yield 56\%). ${ }^{1} \mathrm{H}$ NMR $\left(400 \mathrm{MHz}, \mathrm{CDCl}_{3}\right.$ added several drops of $\left.\mathrm{CD}_{3} \mathrm{COOD}\right) \delta 8.77(\mathrm{~s}, 1 \mathrm{H} ; \mathrm{Ar}-\mathrm{H}), 8.40$ (d, $J=8.0 \mathrm{~Hz}, 1 \mathrm{H}$; ArH), $7.54(\mathrm{~d}, J=2.1 \mathrm{~Hz}, 2 \mathrm{H}$; Ar-H), 7.35 (dd, $J=8.7,2.1 \mathrm{~Hz}, 2 \mathrm{H} ; \mathrm{Ar}-\mathrm{H}), 7.32$ (d, J=8.1 Hz, 1H; Ar-H), 6.95 (d, $J=8.7 \mathrm{~Hz}, 2 \mathrm{H}$; Ar-H), 4.07 (q, $J=7.1 \mathrm{~Hz}, 4 \mathrm{H} ; \mathrm{NCH}_{2} \mathrm{CH}_{3}$ ), 1.17 (t, $J=7.2 \mathrm{~Hz}, 6 \mathrm{H} ; \mathrm{CH}_{2} \mathrm{CH}_{3}$ ). ${ }^{13} \mathrm{C}$ NMR $\left(101 \mathrm{MHz}, \mathrm{CDCl}_{3}\right.$ added several drops of $\left.\mathrm{CD}_{3} \mathrm{COOD}\right) \delta 177.70(\mathrm{CO}), 168.02(\mathrm{COOH}), 157.07$ (C), 151.57 (C), 143.57 (C), 136.82 (C), 132.16 (CH), $129.22(\mathrm{CH}), 127.70$ (C), 126.59 (CH), 124.16 $(\mathrm{CH}), 116.25(\mathrm{CH}), 114.42(\mathrm{C}), 106.75(\mathrm{CH}), 81.63(\mathrm{C}), 38.41\left(\mathrm{CH}_{2}\right), 11.58\left(\mathrm{CH}_{3}\right)$. HRMS (ESI) $\mathrm{m} / \mathrm{z}$ called for $\mathrm{C}_{25} \mathrm{H}_{20} \mathrm{~N}_{4} \mathrm{O}_{7}[\mathrm{M}-\mathrm{H}]^{-:}$: 487.1254; found: $487.1255(z=1)$.

1.3 Synthesis of RhB-Tz 


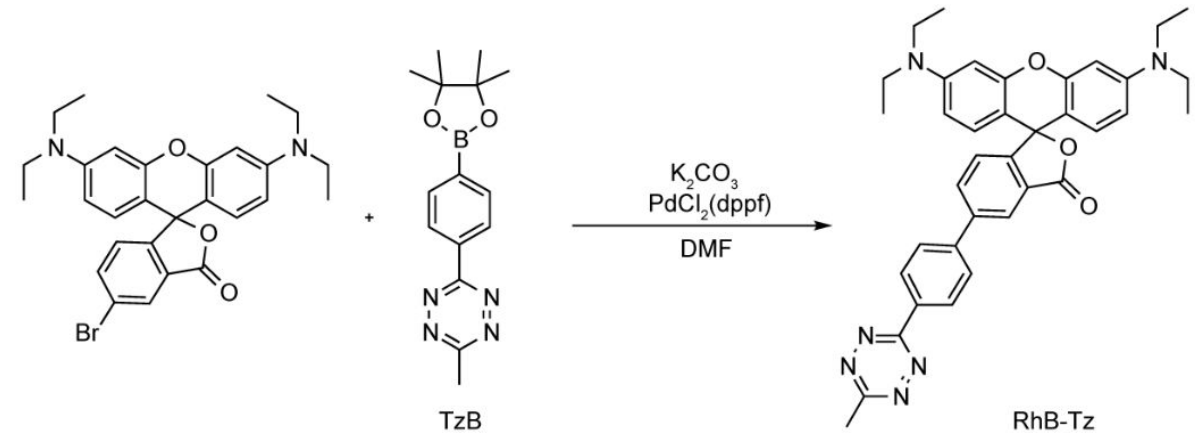

Borate tetrazine (Tz-B) was obtained according to a previous procedure. ${ }^{1}$ A Schlenk flask was charged with $\mathrm{Br}-\mathrm{RhB}(50 \mathrm{mg}, 96 \mu \mathrm{mol}), \mathrm{TzB}(35 \mathrm{mg}, 115 \mu \mathrm{mol}), \mathrm{PdCl}_{2}(\mathrm{dppf})(14 \mathrm{mg}, 19 \mu \mathrm{mol})$ and $\mathrm{K}_{2} \mathrm{CO}_{3}(40 \mathrm{mg}, 288 \mu \mathrm{mol})$. The flask was sealed and evacuated/backfilled with argon for three times. After the completion of the atmosphere exchange, 1,4-dioxane $(10 \mathrm{~mL})$ was added and the reaction mixture was stirred at an inert atmosphere at $100{ }^{\circ} \mathrm{C}$ for $1.5 \mathrm{~h}$. After cooling to room temperature, the solvent was evaporated in vacuo and the crude product was rapidly purified with silica gel column chromatography with a mixture of hexane, ethyl acetate and triethylamine $(1 / 1 / 0.1, \mathrm{v} / \mathrm{v} / \mathrm{v})$ as eluent. The collected solution was dried in vacuo to afford RhB-Tz (40 mg, yield 68\%). ${ }^{1} \mathrm{H}$ NMR (400 MHz, DMSO) $\delta 8.66(\mathrm{~d}, J=7.8 \mathrm{~Hz}, 2 \mathrm{H} ; \mathrm{Ar}-\mathrm{H}), 8.54$ (s, $1 \mathrm{H} ; \mathrm{Ar}-\mathrm{H}), 8.30$ (d, $J=7.8 \mathrm{~Hz}, 1 \mathrm{H} ; \mathrm{Ar}-\mathrm{H}), 8.19$ (d, $J=7.9 \mathrm{~Hz}$, 2H; Ar-H), 7.60 (d, $J=7.5 \mathrm{~Hz}, 1 \mathrm{H}$; Ar-H), $7.21-6.75$ (m, 6H; Ar-H), $3.84-3.51$ (m, 8H; $\mathrm{NCH}_{2} \mathrm{CH}_{3}$ ), $3.05\left(\mathrm{~s}, 3 \mathrm{H} ; \mathrm{C}-\mathrm{CH} H_{3}\right), 1.20\left(\mathrm{t}, J=6.0 \mathrm{~Hz}, 12 \mathrm{H} ; \mathrm{CH}_{2} \mathrm{CH}_{3}\right) .{ }^{13} \mathrm{C}$ NMR $(126 \mathrm{MHz}, \mathrm{DMSO}) \delta 167.65(\mathrm{NCN})$, $163.53(\mathrm{NCN}), 142.34(\mathrm{C}), 141.11(\mathrm{C}), 132.29(\mathrm{C}), 131.08(\mathrm{CH}), 128.73(\mathrm{CH}), 128.47(\mathrm{C}), 96.64(\mathrm{C})$, $45.47\left(\mathrm{NCH}_{2} \mathrm{CH}_{3}\right), 21.35\left(\mathrm{C}-\mathrm{CH}_{3}\right), 12.89\left(\mathrm{CH}_{2} \mathrm{CH}_{3}\right)$. HRMS (ESI) $\mathrm{m} / z$ called for $\mathrm{C}_{37} \mathrm{H}_{36} \mathrm{~N}_{6} \mathrm{O}_{3}[\mathrm{M}+\mathrm{H}]^{+}$: 613.2927; found: $613.2928(z=1)$.

\subsection{Synthesis of NOR-Tz}
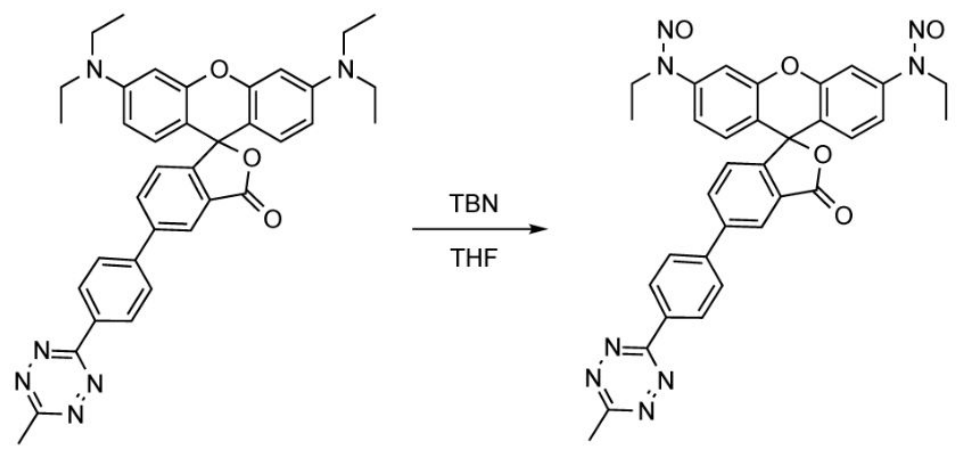

NOR-Tz

RhB-Tz (60 mg, $98 \mu \mathrm{mol})$ was dissolved in dry tetrahydrofuran $(6 \mathrm{~mL})$ and butyl nitrite $(120 \mathrm{uL}$, $1.01 \mathrm{mmol}$ ) was added. The mixture was heated to $60^{\circ} \mathrm{C}$ and stirred for $1 \mathrm{~h}$. After the completion of the reaction, solvent was removed under reduced pressure. The crude product was further purified through silica gel column chromatography with a mixture of hexane and ethyl acetate $(1 / 1, \mathrm{v} / \mathrm{v})$ as eluent. The crude product was further purified by preparative HPLC with a mixture of hexane, and ethyl acetate (68/32, $\mathrm{v} / \mathrm{v}$ ) as mobile phase. The collected solution was dried in vacuo to afford NOR-Tz ( $25 \mathrm{mg}$, yield $42 \%$ ). ${ }^{1} \mathrm{H}$ NMR $\left(400 \mathrm{MHz}, \mathrm{CDCl}_{3}\right.$ added several drops of $\left.\mathrm{CD}_{3} \mathrm{COOD}\right) \delta 8.73$ (d, $J=7.2 \mathrm{~Hz}, 2 \mathrm{H}$; Ar-H), 8.36 (s, $1 \mathrm{H}$; Ar-H), 8.03 (d, $J=7.5 \mathrm{~Hz}, 1 \mathrm{H}$; Ar-H), 7.89 (d, $J=7.0 \mathrm{~Hz}, 2 \mathrm{H}$; Ar-H), 7.53 (s, 2H; Ar-H), $7.43-7.30$ (m, 3H; Ar-H), 7.04 (d, $J=8.1 \mathrm{~Hz}, 2 \mathrm{H} ; \mathrm{Ar}-\mathrm{H}), 4.08\left(\mathrm{~d}, J=6.1 \mathrm{~Hz}, 4 \mathrm{H} ; \mathrm{NCH}_{2} \mathrm{CH}_{3}\right), 3.12\left(\mathrm{~s}, 3 \mathrm{H} ; \mathrm{CCH}_{3}\right)$, 
$1.18\left(\mathrm{~s}, 6 \mathrm{H} ; \mathrm{CH}_{2} \mathrm{CH}_{3}\right) .{ }^{13} \mathrm{C} \mathrm{NMR}\left(101 \mathrm{MHz}, \mathrm{CDCl}_{3}\right.$ added several drops of $\left.\mathrm{CD}_{3} \mathrm{COOD}\right) \delta 168.75(\mathrm{CO})$, $167.44(\mathrm{NCN}), 163.71(\mathrm{NCN}), 152.17(\mathrm{C}), 151.72(\mathrm{C}), 143.46(\mathrm{C}), 142.84(\mathrm{C}), 142.62(\mathrm{C}), 134.54(\mathrm{CH})$, $131.92(\mathrm{C}), 129.42(\mathrm{C}), 128.73(\mathrm{CH}), 128.13(\mathrm{CH}), 127.13(\mathrm{CH}), 124.43(\mathrm{CH}), 123.81(\mathrm{CH}), 116.91(\mathrm{CH})$, $114.39(\mathrm{C}), 106.70(\mathrm{CH}), 81.50(\mathrm{C}), 38.43\left(\mathrm{NCH}_{2} \mathrm{CH}_{3}\right), 21.22\left(\mathrm{CCH}_{3}\right), 11.72\left(\mathrm{CH}_{2} \mathrm{CH}_{3}\right)$. HRMS (ESI) $m / z$ called for $\mathrm{C}_{33} \mathrm{H}_{26} \mathrm{~N}_{8} \mathrm{O}_{5}[\mathrm{M}+\mathrm{Na}]^{+}$: 637.1924; found: $637.1927(z=1)$.

1.5 Other involved compounds

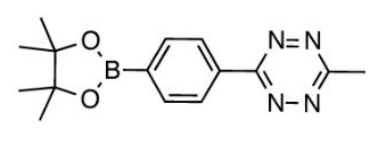

TzB

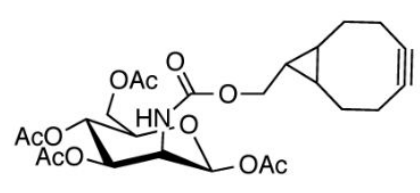

$\mathrm{BCN}-\mathrm{Ac}_{4} \mathrm{ManN}$

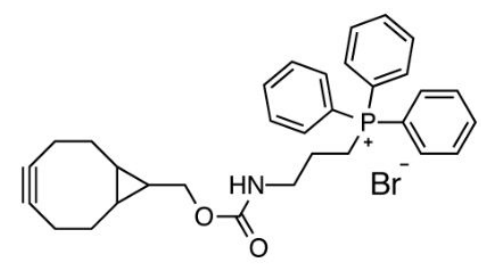

BCN-TPP

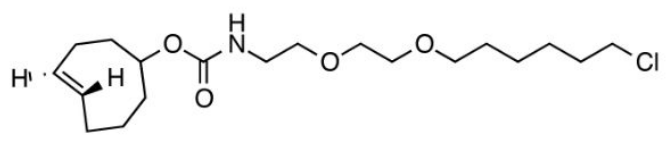

TCO-Halo

TzB, ${ }^{1} \mathrm{BCN}-\mathrm{Ac}_{4} \mathrm{ManN},{ }^{2} \mathrm{BCN}-\mathrm{TPP},{ }^{3} \mathrm{TCO}-\mathrm{Halo}^{4}$ were synthesized according to reported procedures. 


\section{Spectroscopic study}

\subsection{Method}

\subsubsection{Relative fluorescence quantum yield}

The relative quantum yield (precision: $\pm 10 \%$ ) of a sample was calculated according to the equation below:

$$
\Phi_{\mathrm{s}}=\Phi_{\mathrm{st}} \times \frac{\mathrm{A}_{\mathrm{st}}}{\mathrm{A}_{\mathrm{s}}} \times \frac{\mathrm{I}_{\mathrm{s}}}{\mathrm{I}_{\mathrm{st}}} \times \frac{\mathrm{n}_{\mathrm{s}}^{2}}{\mathrm{n}_{\mathrm{st}}^{2}}
$$

$\Phi$ was the quantum yield. A was the absorption at the excitation wavelength. I was the integral of fluorescence. $\mathrm{n}$ was the refractive index of the solvents. The subscripts of these elements were listed as: ${ }_{\mathrm{s}}$ was the sample and ${ }_{\mathrm{st}}$ was the standard (reference sample).

\subsubsection{Photoconversion quantum yield}

The uncaging process of nitroso-rhodamines is a consecutive photochemical process with two-step photoreactions. The photoconversion quantum yields are determined following the method described in reference. ${ }^{5}$ Herein, we briefly describe the implemented mathematical model for our study. The two-step photochemical process could be simplified as below:

$$
\mathrm{A} \stackrel{h v}{\rightarrow} \mathrm{B} \stackrel{h v}{\rightarrow} \mathrm{C}
$$

$\mathrm{A}$ is the caged fluorophore, i.e. substrate. B is the intermedia obtained after photolysis of A. C is the final obtained photoproducts. Then, the rate equations could be written as:

$$
\begin{aligned}
& \frac{-\mathrm{dC}_{\mathrm{A}}}{\mathrm{dt}}=\phi_{\mathrm{p} 1} \mathrm{I}\left(1-10^{-\mathrm{A}_{\mathrm{t}}}\right) \frac{\left(\epsilon_{\mathrm{A}} \mathrm{bC}_{\mathrm{A}}\right)}{\mathrm{A}_{\mathrm{t}}} \\
& \frac{\mathrm{dC}_{\mathrm{B}}}{\mathrm{dt}}=\mathrm{I}\left(1-10^{-\mathrm{A}_{\mathrm{t}}}\right) \frac{\left(\phi_{\mathrm{p} 1} \epsilon_{\mathrm{A}} \mathrm{bC}_{\mathrm{A}}-\phi_{\mathrm{p} 2} \epsilon_{\mathrm{B}} \mathrm{bC} \mathrm{B}_{\mathrm{B}}\right)}{\mathrm{A}_{\mathrm{t}}} \\
& \frac{\mathrm{dC}_{\mathrm{C}}}{\mathrm{dt}}=\phi_{\mathrm{p} 2} \mathrm{I}\left(1-10^{-\mathrm{A}_{\mathrm{t}}}\right) \frac{\left(\epsilon_{\mathrm{B}} \mathrm{bC}_{\mathrm{B}}\right)}{\mathrm{A}_{\mathrm{t}}}
\end{aligned}
$$

Here, $\mathrm{C}_{\mathrm{A}}, \mathrm{C}_{\mathrm{B}}, \mathrm{C}_{\mathrm{C}}$ are the concentrations of $\mathrm{A}, \mathrm{B}$ and $\mathrm{C}$. $\mathrm{I}$ is the $365 \mathrm{~nm}$ light intensity $(\sim 1.5 \times 10-6$ einstein $\left.\cdot \mathrm{s}^{-1} \cdot \mathrm{L}^{-1}\right) . \Phi_{\mathrm{p} 1}, \Phi_{\mathrm{p} 2}$ is the photoconversion quantum yield of $\mathrm{A}$ to $\mathrm{B}$ or $\mathrm{B}$ to $\mathrm{C}$. $\varepsilon_{\mathrm{A}}, \varepsilon_{\mathrm{B}}$ are the absorption of $\mathrm{A}$ or $\mathrm{B}$ at excitation wavelength. $\mathrm{A}_{t}$ is the total absorption of the samples at excitation wavelength, $A_{t}=b\left(\epsilon_{A} C_{A}+\epsilon_{B} C_{B}+\epsilon_{C} C_{C}\right)$. $b$ is the path length of the cuvette $(1 \mathrm{~cm})$.

During the photoactivation, the absorption spectra matrix $A\left(N_{t} \times N_{\lambda}\right.$ matrix: $N_{t}$ is the time points; $N_{\lambda}$ is the wavelength) is the multiplication of $C$ (concentration matrix: $N_{t} \times N_{s}$ matrix; $N_{s}$ is the number of involved species) and $\mathrm{E}$ (spectra matrix: $\mathrm{N}_{\mathrm{s}} \times \mathrm{N}_{\lambda}$ ).

$$
\mathbf{A}=\mathbf{C} \times \mathbf{E}
$$

Therefore, the problem to find the photoconversion quantum yield from experimental absorption data could be solved through an iterative regression analysis on the basis of above mathematical model. This analysis contains two stages: the predication of absorption spectra (stage I) and the optimization of conversion quantum yields (stage II). Unknown parameters are initialized at first, including the conversion quantum yields and constructing zero arrays of unknown spectra $\left(\mathrm{E}_{\mathrm{fit}}\right)$ (the absorption spectrum of $\mathrm{A}$ is experimentally determined priorly). During stage I, a temporal concentration matrix (C) is calculated by the integration of equations (SS2)-(SS4). With $\mathbf{C}$ and experimental $\mathbf{A}_{\text {exp }}$, the spectra matrix ( $\left.\mathbf{E}_{\mathrm{fit}}\right)$ is predicted through equation (SS5). During stage II, an absorption spectra matrix $\mathbf{A}_{\text {fit }}$ is calculated as $\mathbf{C} \times$ $\mathbf{E}_{\mathrm{fit}}$. Through the first stage analysis, the estimation absorption matrix could be calculated as $\mathbf{A}_{\mathrm{fit}}=\mathbf{C} \times$ $\mathrm{E}_{\mathrm{fit}}$. non-linear least-squares analysis was performed on optimizing $\Phi_{\mathrm{p} 1}, \Phi_{\mathrm{p} 2}$ to minimize the sum of residues $\sum\left(\mathbf{A}_{\mathrm{f} i t}-\mathbf{A}_{\mathrm{exp}}\right)^{2}$. Every time a new optimized $\Phi_{\mathrm{p} 1}, \Phi_{\mathrm{p} 2}$ is obtained, a new spectra matrix $\mathrm{E}_{\mathrm{fit}}$ is 
updated by the approach described in stage I. This two-stage regression analysis is repeated until convergence (or the arrival of upper calculation limits).

2.2 Spectral Analysis
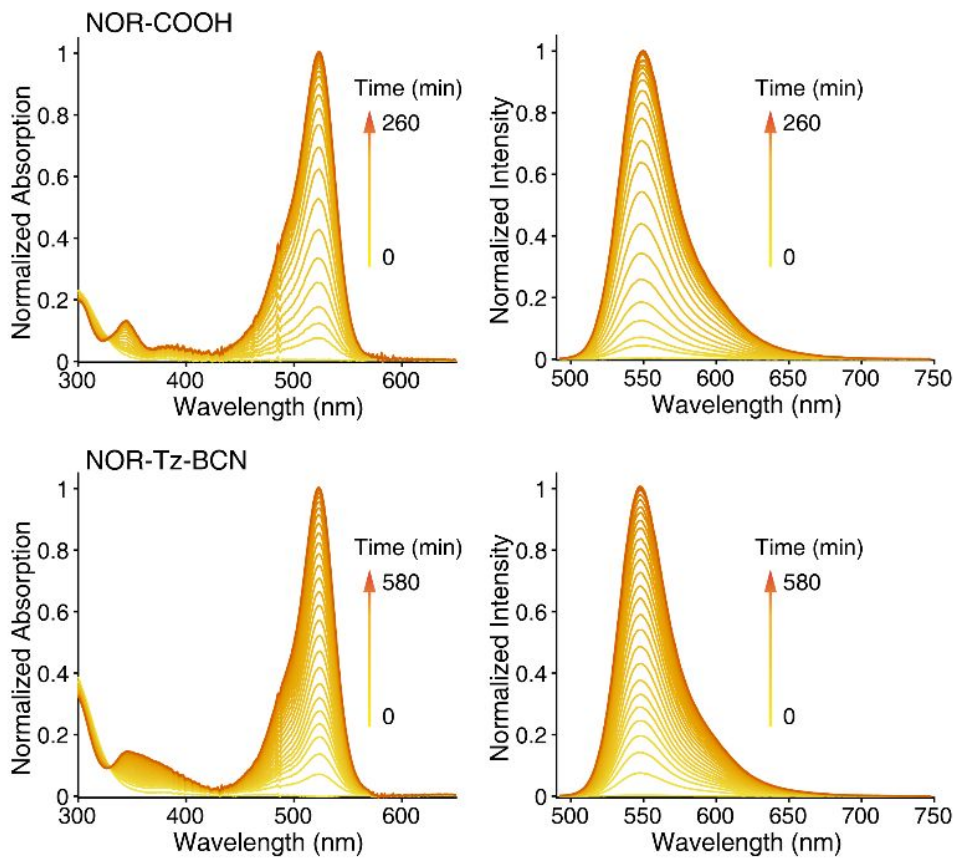

Figure S1. Normalized absorption and fluorescent spectra of NOR-COOH and NOR-Tz-BCN during photoactivation under $365 \mathrm{~nm}$ light irradiation.

Nitroso-caged rhodamines showed none visible absorption band and none fluorescence in aqueous solution. Upon UV irradiation, these fluorophores generated visible absorption and fluorescence band, and with the prolongation of irradiation time, these visible bands gradually increased to their maximum, as shown in Figure S1. This turn-on behavior of NOR is robust, showing dark-to-bright contrasts over 1000. In accordance with their structural similarity to rhodamine $6 \mathrm{G}$, the photoproducts of NOR present unity quantum yields approaching $\sim 1$. The dramatical fluorescence enhancement of NOR constitutes a robust dark-bright transform and the high brightness of the photoproduct further strengthens its singlemolecule brightness, facilitating super-resolution imaging.

The uncaging quantum yields was further quantitatively determined. Nitroso-caged rhodamines probably photolyze through a two-step consecutive procedure (Scheme S1). Therefore, two photoconversion quantum yields were determined through the method of regression analysis ${ }^{5}$ (Figure S2; details of the implemented mathematical model were described in section 2.1.2). The absorption spectra of the intermedia and the photoproducts are predicted during the analysis (Figure S2a and d). The estimated spectra of final photoproducts are in accordance with the experimental results (Figure S1). Moreover, the fitting results on the temporal evolvement of absorption peak matches the experimental data (Figure S2c and f). Single-caged intermedia shows a relatively weaker absorption band, compared to that of final photoproducts, probably credited to its asymmetric structures. The fitting results further provided the temporal evolvement of concentrations during photoactivation (Figure S2b and e). The primary photoconversion yields for NOR-COOH and NOR-Tz-BCN (ca. 0.16 and 0.16) are higher than their secondary photoconversion yields (ca. 0.10 and 0.027). The decrement on the secondary photoconversion yield is probably caused by the radiative decay of the intermedia (single nitroso caged 
fluorophore), as their analogues presented moderate visible fluorescence. ${ }^{6,7}$ For NOR-Tz-BCN, its secondary quantum yield (ca. 0.027 vs ca. $0.10 \mathrm{NOR}-\mathrm{COOH}$ ) is lower than that of NOR-COOH. This result might be rationalized as a competing absorption from its pyridazine unit, which probably does not uncage the distanced nitroso group.

In short, nitroso-rhodamines exhibit advantageous photophysical properties with magnificent darkto-bright contrast and high brightness, facilitating its deployment in localization-based super-resolution imaging as well as other advanced imaging.

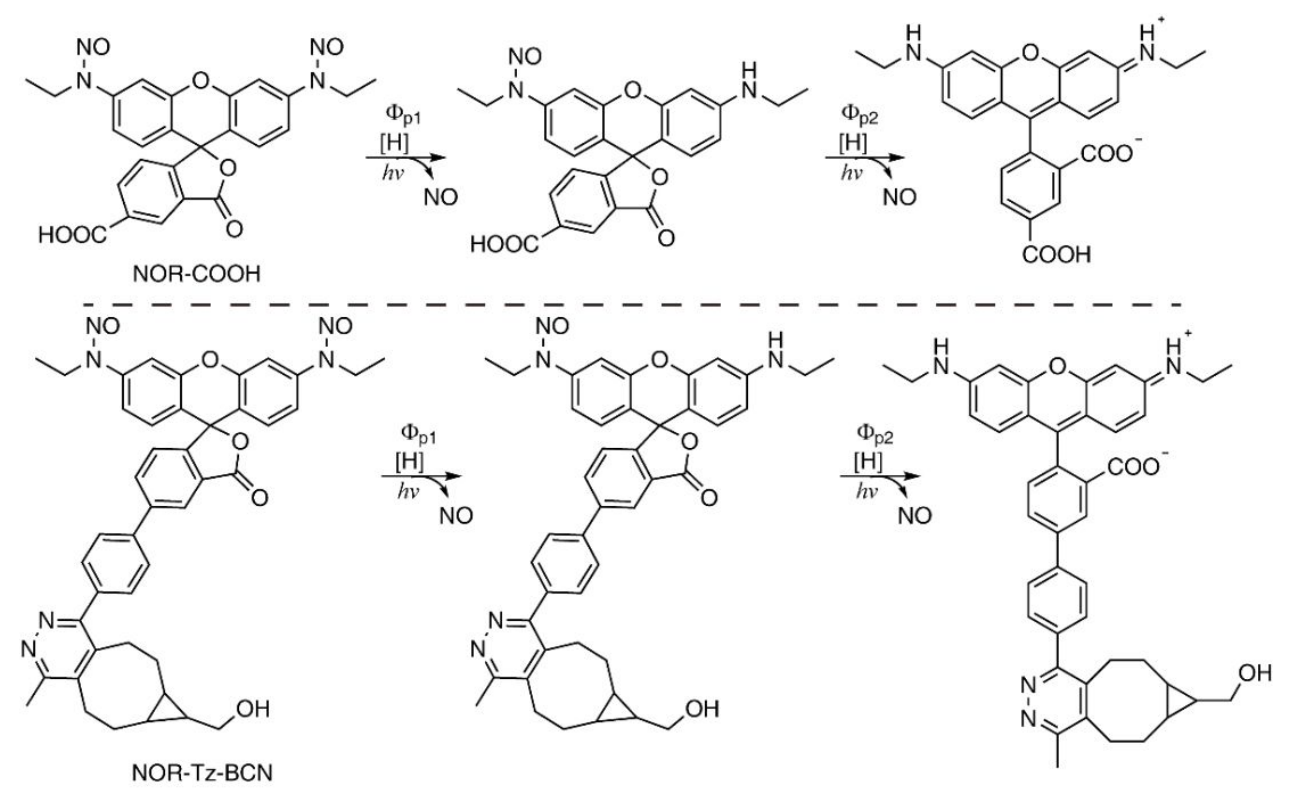

Scheme S1. Proposed photoactivation process of NOR-COOH and NOR-Tz-BCN 

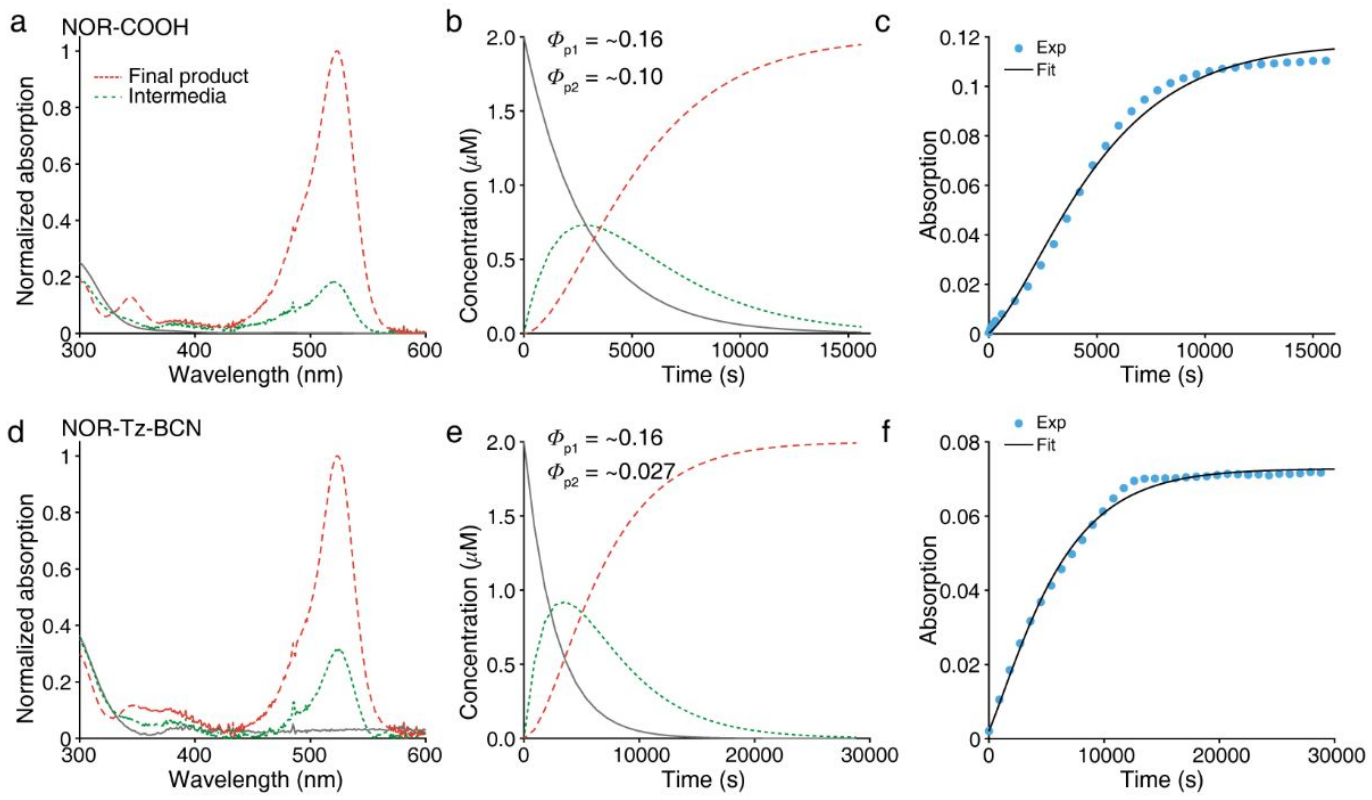

Figure S2. Determination of photoconversion quantum yields for the two-step photochemical process of NOR$\mathrm{COOH}$ and NOR-Tz-BCN. (a) and (d) exhibit the fitted absorption spectra of intermedia and final products, in comparison with the experimental absorption spectra of their corresponding caged fluorophores. (b) and (e) show estimated concentration plots of substrates during photoactivation. The plots of NOR-COOH or NOR-Tz-BCN were colored in black, the plots of intermedia were colored in green and the plots of final photoproducts were colored in red. (c) and (f) exhibit the acquired absorption data at peak wavelength (524 nm for NOR-COOH and $523 \mathrm{~nm}$ for NOR-Tz$\mathrm{BCN}$, blue dots). The black lines were the fitting curves obtained from the two-step photochemical model.

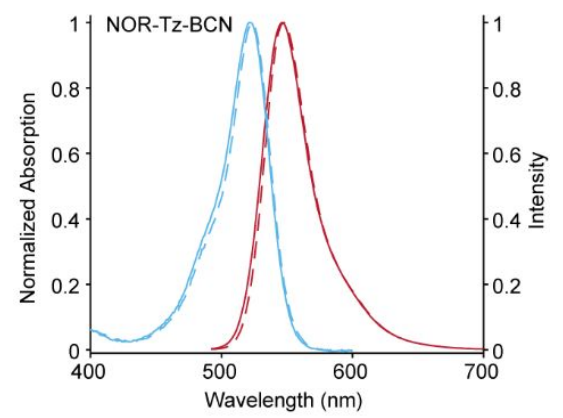

Figure S3. Spectral comparison on photoproducts from NOR-Tz-BCN in PBS solution ( $\mathrm{pH}=7.4$, contained $50 \%$ $\mathrm{v} / \mathrm{v}$ methanol) through green light and UV light photoactivation. Absorption and fluorescent spectra are colored in blue and red, respectively.

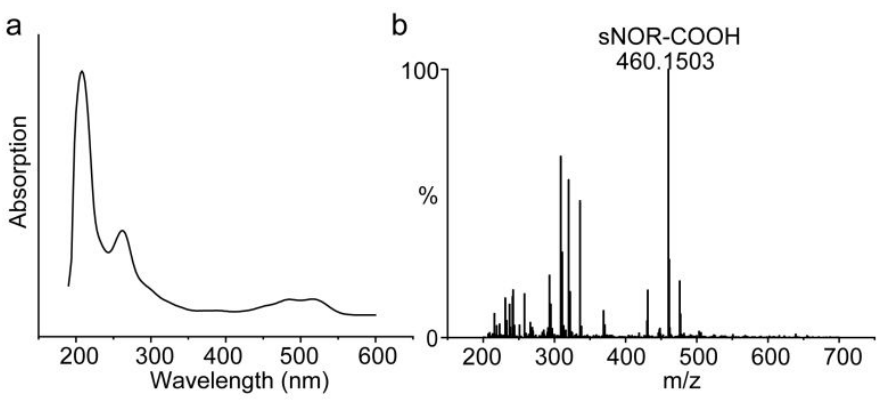

Figure S4. The absorption (a) and high-resolution mass (b) spectra of photoproducts at $t_{\mathrm{R}}=20 \mathrm{~min}$. 


\section{Single-molecule analysis}
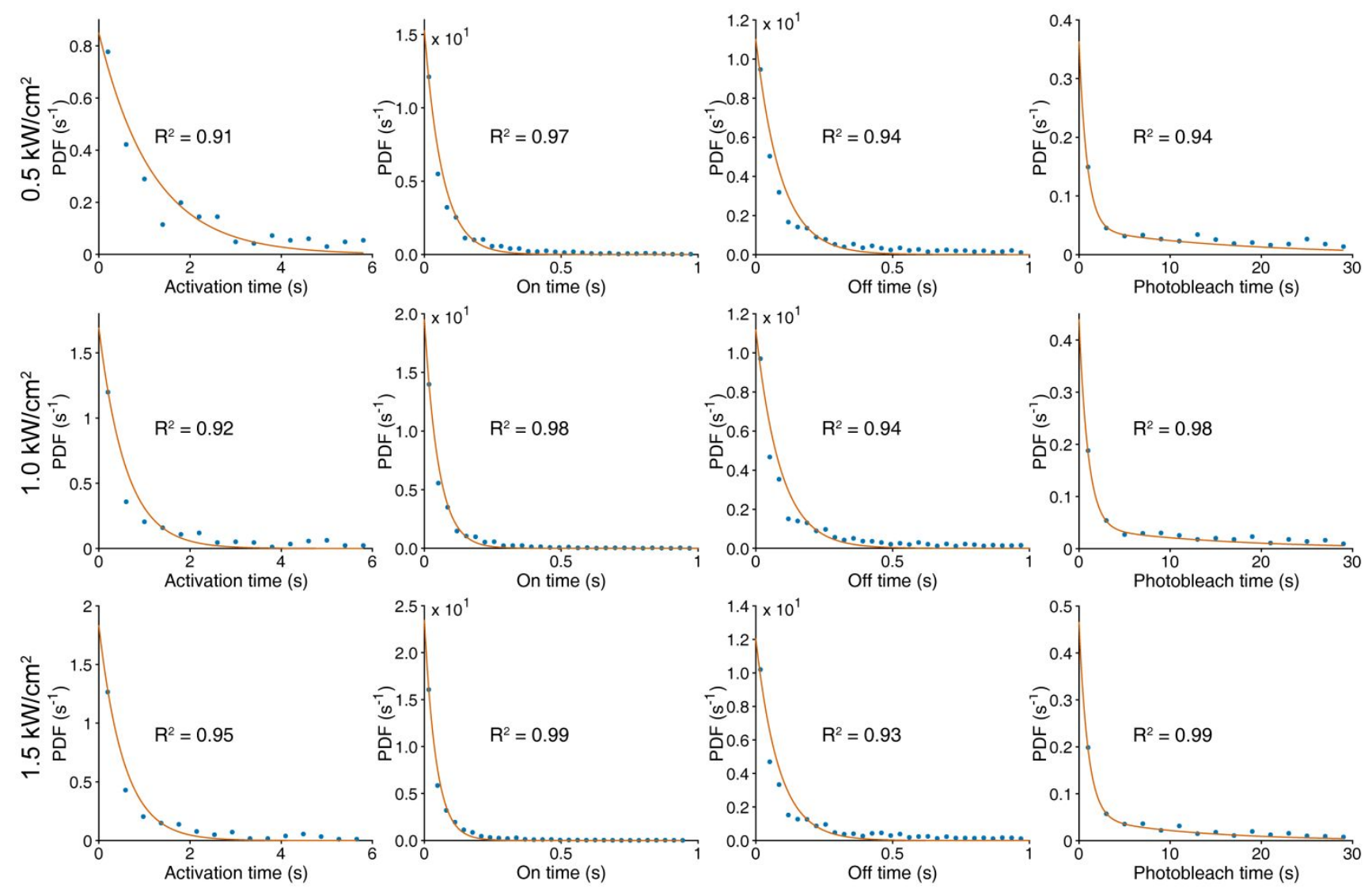

Figure S5. The probability density function (PDF) of activation, on, off, photobleach times for NOR under various irradiation powers. The PDFs fitted well to single or double exponential functions.

\section{Imaging analysis}
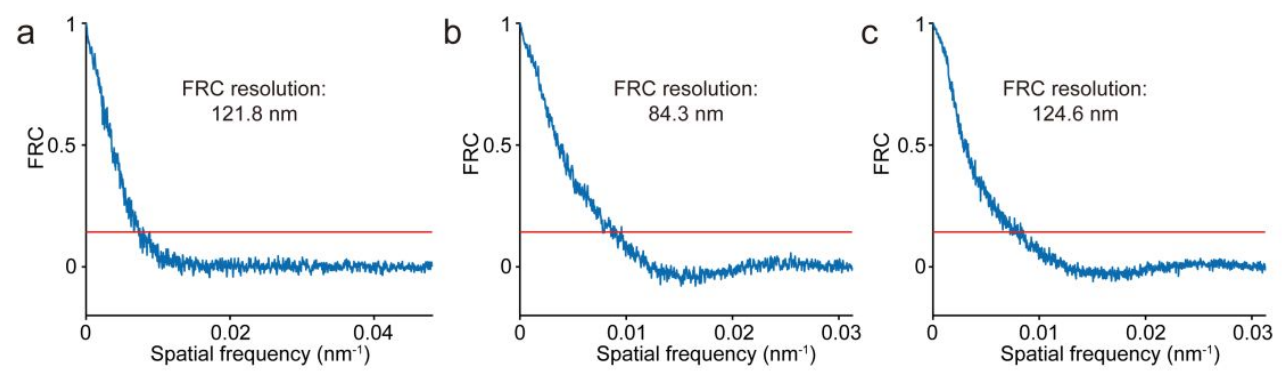

Figure S6. Fourier ring correlation analysis of localizations in Figure 5a (a), Figure 6c (b), Figure 6d (c).

To validate the metabolic labeling through NOR-Tz, we have performed a comparison study on cells incubated with and without BCN-Ac ${ }_{4} \mathrm{ManN}$. As shown in Figure S7, when the unnatural mannosamines are removed, cells stained with NOR-Tz show neglectable fluorescence after photoactivation; meanwhile, robust fluorescence is detected in cells incubated with unnatural mannosamines. This sharp contrast indicates that NOR could successfully label into the unnatural mannosamine in living cells through the cycloaddition reaction between tetrazine and $\mathrm{BCN}$.

We have further tracked the distribution of engineered mannosamines in living cells at different time periods. Figure S8 shows that fluorescence from NOR centralized on regions proximate to the nucleus of the cell with complex network morphology, probably fitting the shape of endoplasmic reticulum and 
mitochondria. Following the prolongation of $\mathrm{BCN}-\mathrm{Ac}_{4} \mathrm{ManN}$ administration, the contrast of net structure decreases with the generation of broadly distributed fluorescence from living cells. This result might relate to the accumulation of glycans on the plasma membrane through the biosynthetic machinery.

To verify the glycans labeling, we further studied the plasma membrane of these cells (after $48 \mathrm{~h}$ of $\mathrm{BCN}-\mathrm{Ac}_{4} \mathrm{ManN}$ incubation) with a TIRF microscopy. The evanescent wave of total internal reflection restricts the excitation depth to $<\sim 200 \mathrm{~nm}$, permitting the selective studying of plasma membrane adhering to the coverslips. As shown in Figure S9, fluorescence signals of NOR generate on the plasma membrane after photoactivation. This result substantiates that NOR was successfully labeled to glycans on the plasma membrane through metabolic labeling strategy.
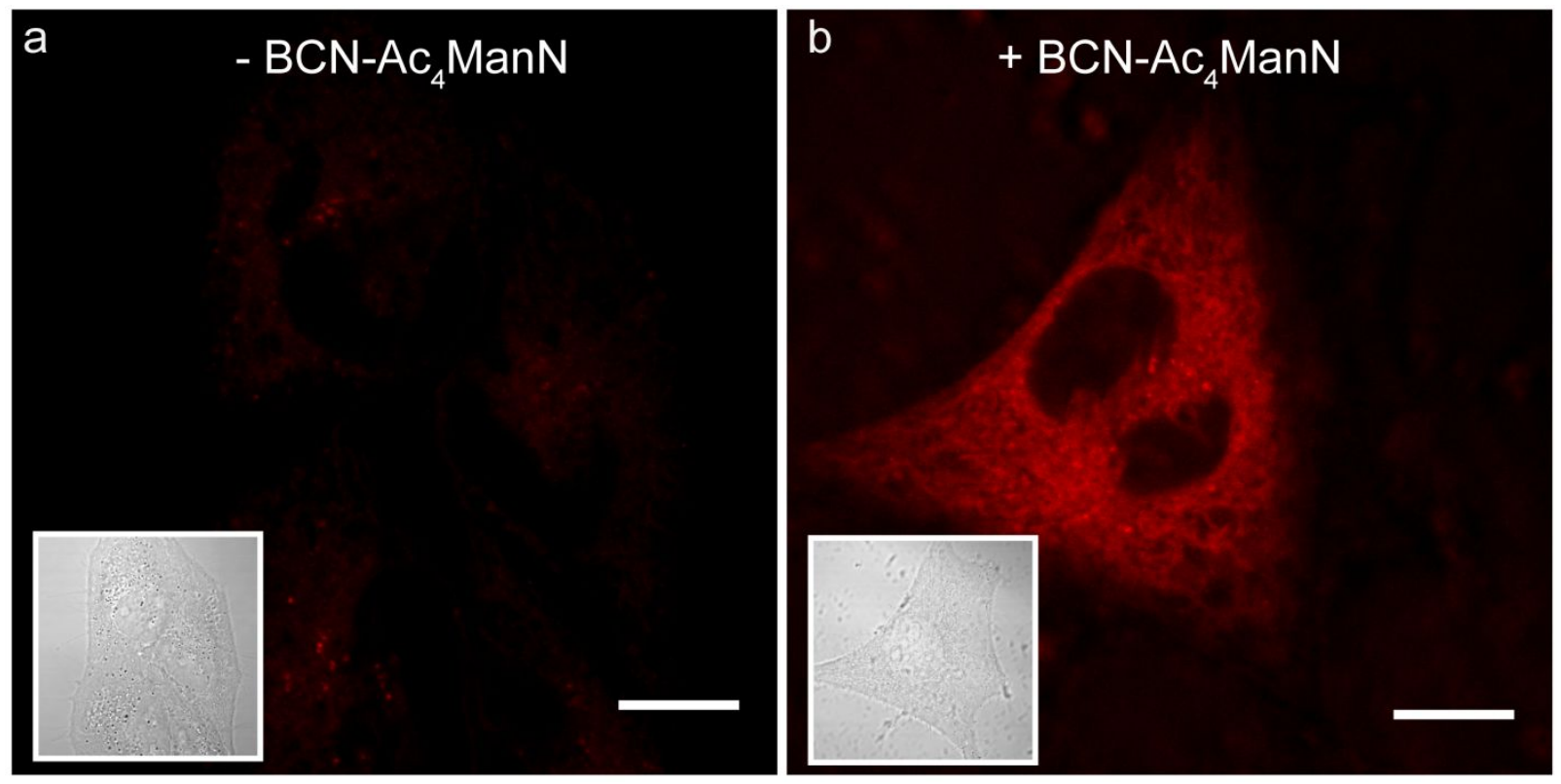

Figure S7. Confocal fluorescence imaging of NOR-Tz in live HeLa cells. (a) Cells in control group were cultured in normal growth medium without the addition of unnatural mannose. (b) Cells in sample group were incubated with $\mathrm{BCN}-\mathrm{Ac}_{4} \mathrm{ManN}$. Cells from control and sample groups were stained, photoactivated and imaged under identical conditions. Scale bars: $10 \mu \mathrm{m}$. 


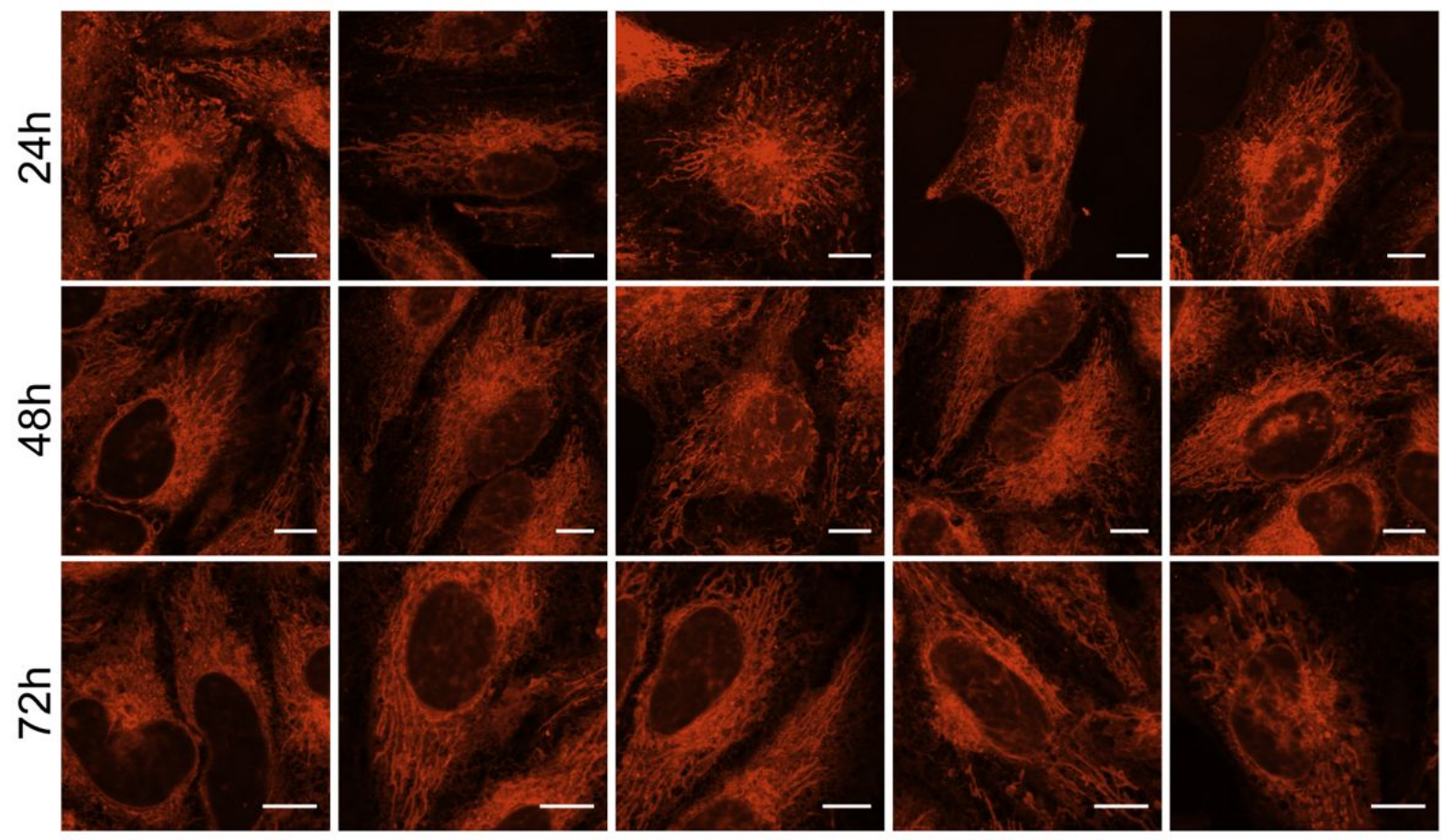

Figure S8. Confocal fluorescence imaging of NOR-Tz in live HeLa cells with different administration time of $\mathrm{BCN}-\mathrm{Ac}_{4} \mathrm{ManN}$. Scale bars: $10 \mu \mathrm{m}$.

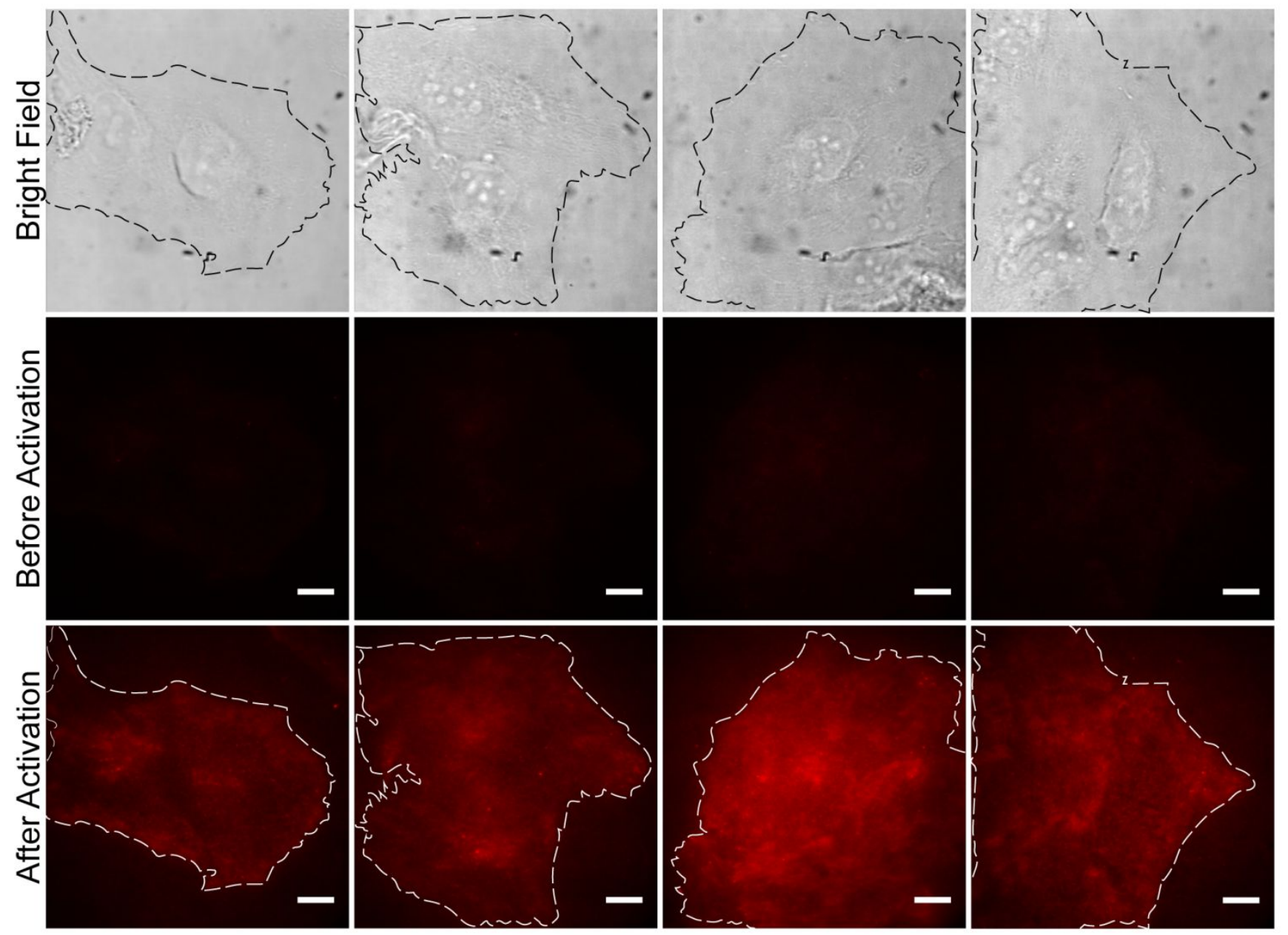

Figure S9. TIRF Imaging of plasma membrane (attached to the surface of coverslips) on live HeLa cells. Four typical cases are presented: each row respectively shows their bright field images, TIRF images before photoactivation and after photoactivation. Scale bars: $10 \mu \mathrm{m}$. 


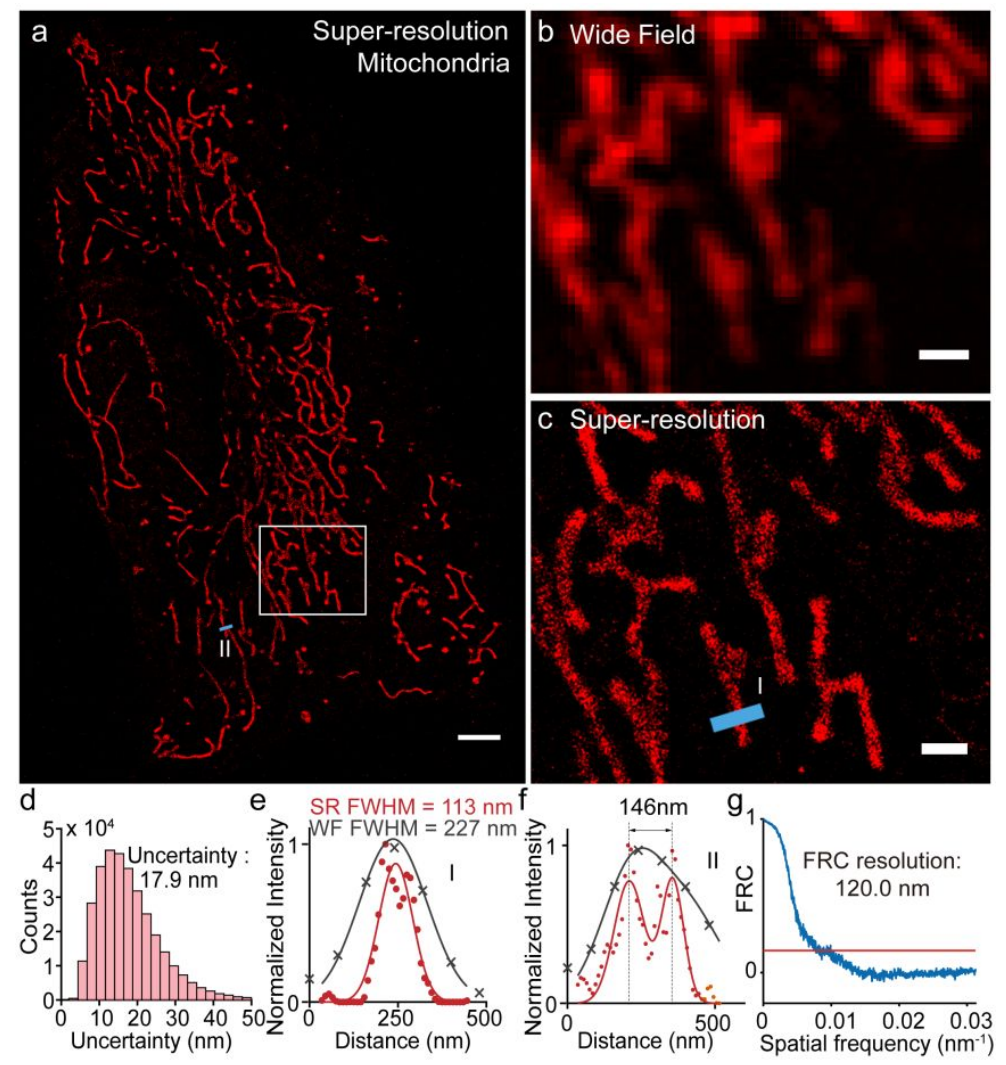

Figure S10. Analysis of the super-resolution image of mitochondria in an entire live HeLa cell. (a) The same superresolution image as Figure 7g. Conventional image (b) and super-resolution image (c) of highlightened region in (a). The acquisition was conducted at $100 \mathrm{~Hz}$. (d) Histogram of localization uncertainties from the reconstruction. (e, f) Intensity profiles of mitochondria highlightened with blue lines in super-resolution images (c, a). The data were fitted with single or double gaussian functions. (g) Fourier ring correlation analysis of the reconstruction. Scale bars: $4 \mu \mathrm{m}$ (a); $0.5 \mu \mathrm{m}$ (b, c).

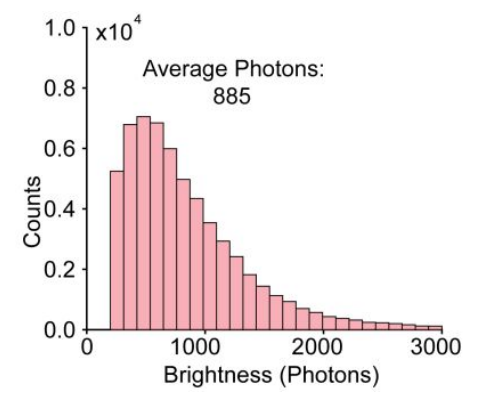

Figure S11. Histogram of single-molecule brightness in super-resolution imaging H2B fusion proteins labeled with NOR (Figure $8 b$ ). 

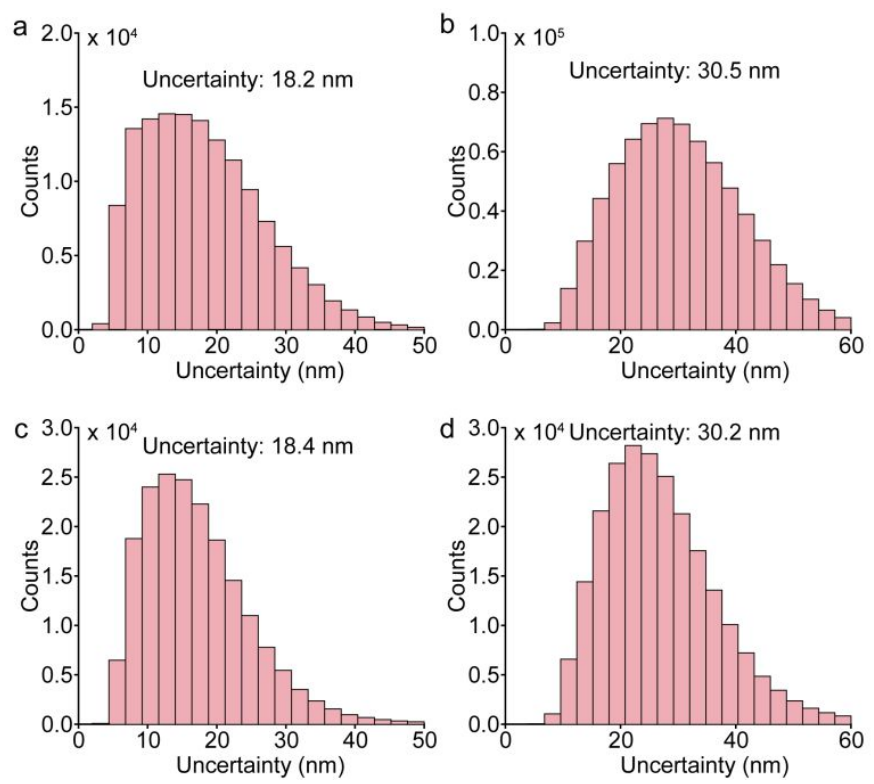

Figure S12. Histogram of localization uncertainties in Figure 6c (a), Figure 6d (b), Figure S13a (c) and Figure S13b (d).
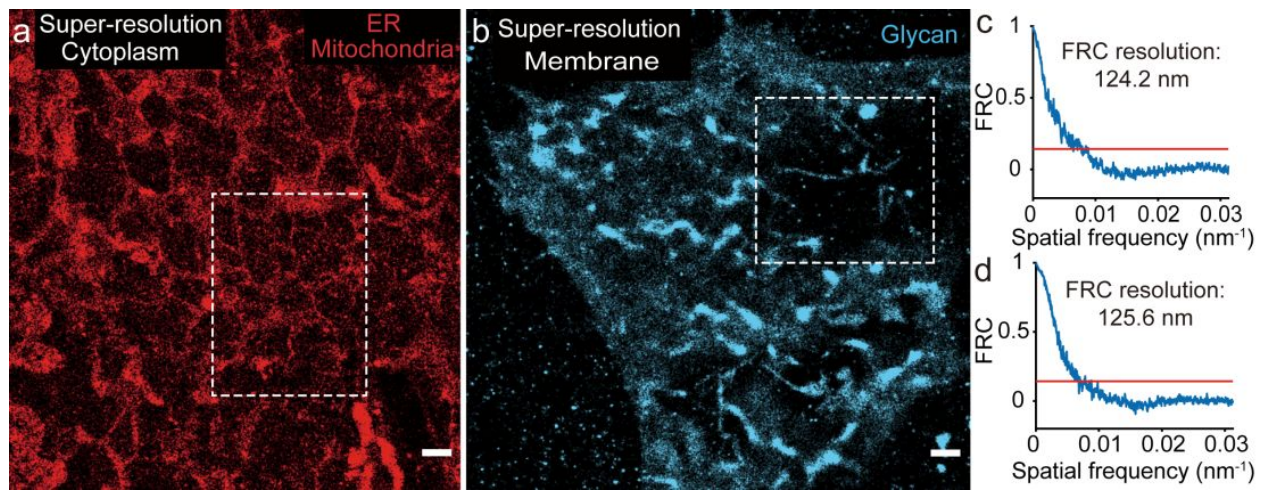

Figure S13. Super-resolution imaging of cytoplasm (a) and plasma membrane (b) in living Hela cells stained with NOR labeled to engineered mannosamines. The acquisitions were conducted at $200 \mathrm{~Hz}$. (c and d) Fourier ring correlation analysis of the reconstruction ( $a$ and $b$ ). Scale bars: $1 \mu \mathrm{m}$. 


\section{Movies descriptions}

Movie S1. Blinking signals from uncaged NOR on microtubules of fixed cells. The imaging was performed with a single $532 \mathrm{~nm}$ laser for both excitation and photoactivation. The exposure time for single image was $50 \mathrm{~ms}$. Video rate: $20 \mathrm{~Hz}$.

Movie S2. Blinking signals from uncaged NOR labeled to manosamines in cytoplasm of a living cell. The imaging was performed with a single $532 \mathrm{~nm}$ laser for both excitation and photoactivation. The exposure time for single image was $10 \mathrm{~ms}$. Video rate: $50 \mathrm{~Hz}$.

Movie S3. Blinking signals from uncaged NOR labeled to glycancs on the membrane of a living cell. The imaging was performed with a single $532 \mathrm{~nm}$ laser for both excitation and photoactivation. The exposure time for single image was $10 \mathrm{~ms}$. Video rate: $50 \mathrm{~Hz}$.

Movie S4. Blinking signals from uncaged NOR on mitochondria from a whole living cell. The imaging was performed with a single $532 \mathrm{~nm}$ laser for both excitation and photoactivation. The exposure time for single image was $10 \mathrm{~ms}$. Video rate: $60 \mathrm{~Hz}$.

Movie S5. Blinking signals from uncaged NOR conjugated to H2B proteins through protein-tag technology in a living cell. The imaging was performed with a single $532 \mathrm{~nm}$ laser for both excitation and photoactivation. The exposure time for single image was $10 \mathrm{~ms}$. Video rate: $25 \mathrm{~Hz}$.

Movie S6. Blinking signals from uncaged NOR on mitochondria in a living cell. The imaging was performed with a single $532 \mathrm{~nm}$ laser for both excitation and photoactivation. The exposure time for single image was $5 \mathrm{~ms}$. Video rate: $100 \mathrm{~Hz}$. 


\section{Characterization spectra}

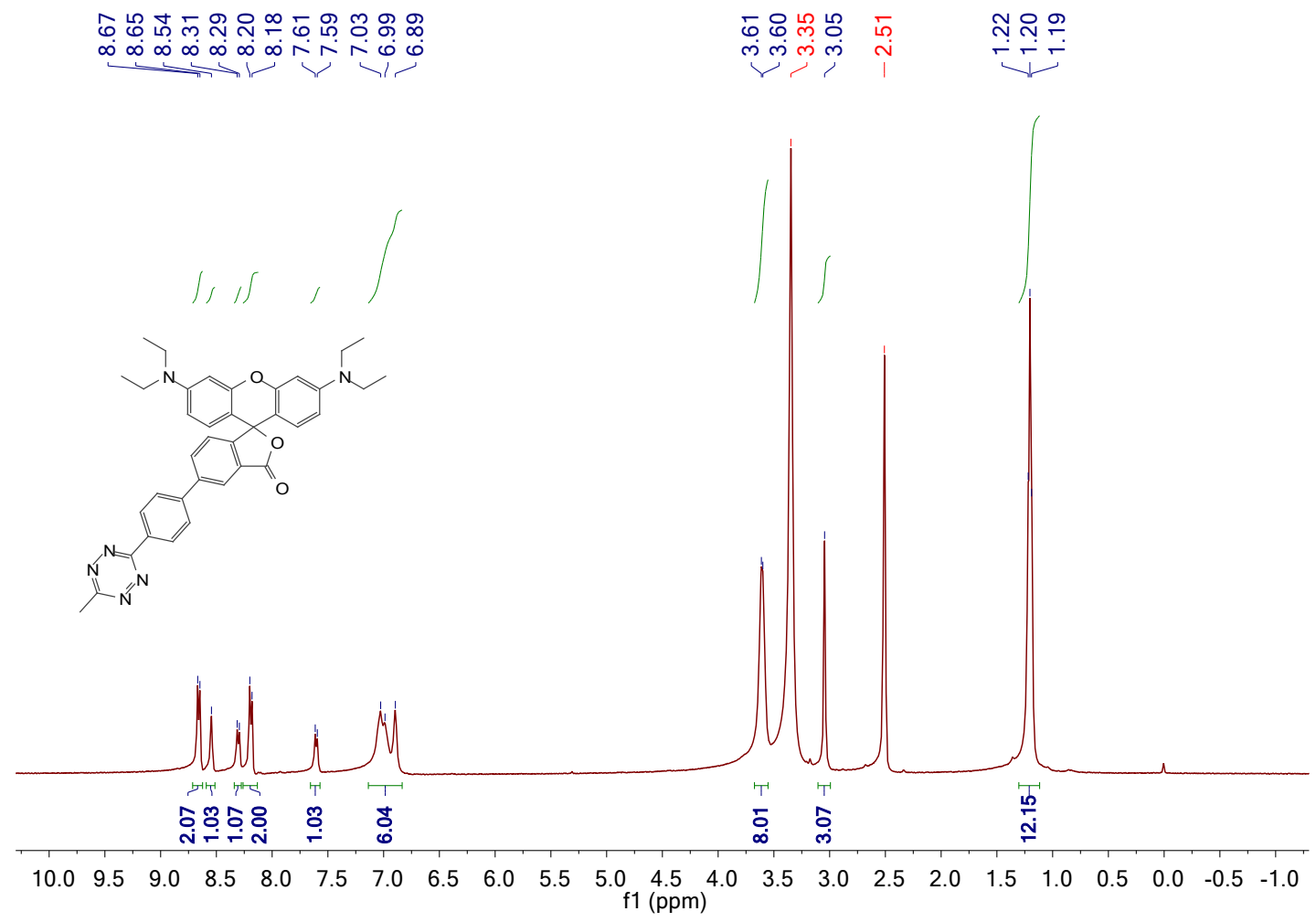

Figure S14. ${ }^{1} \mathrm{H}$ NMR spectrum of RhB-Tz

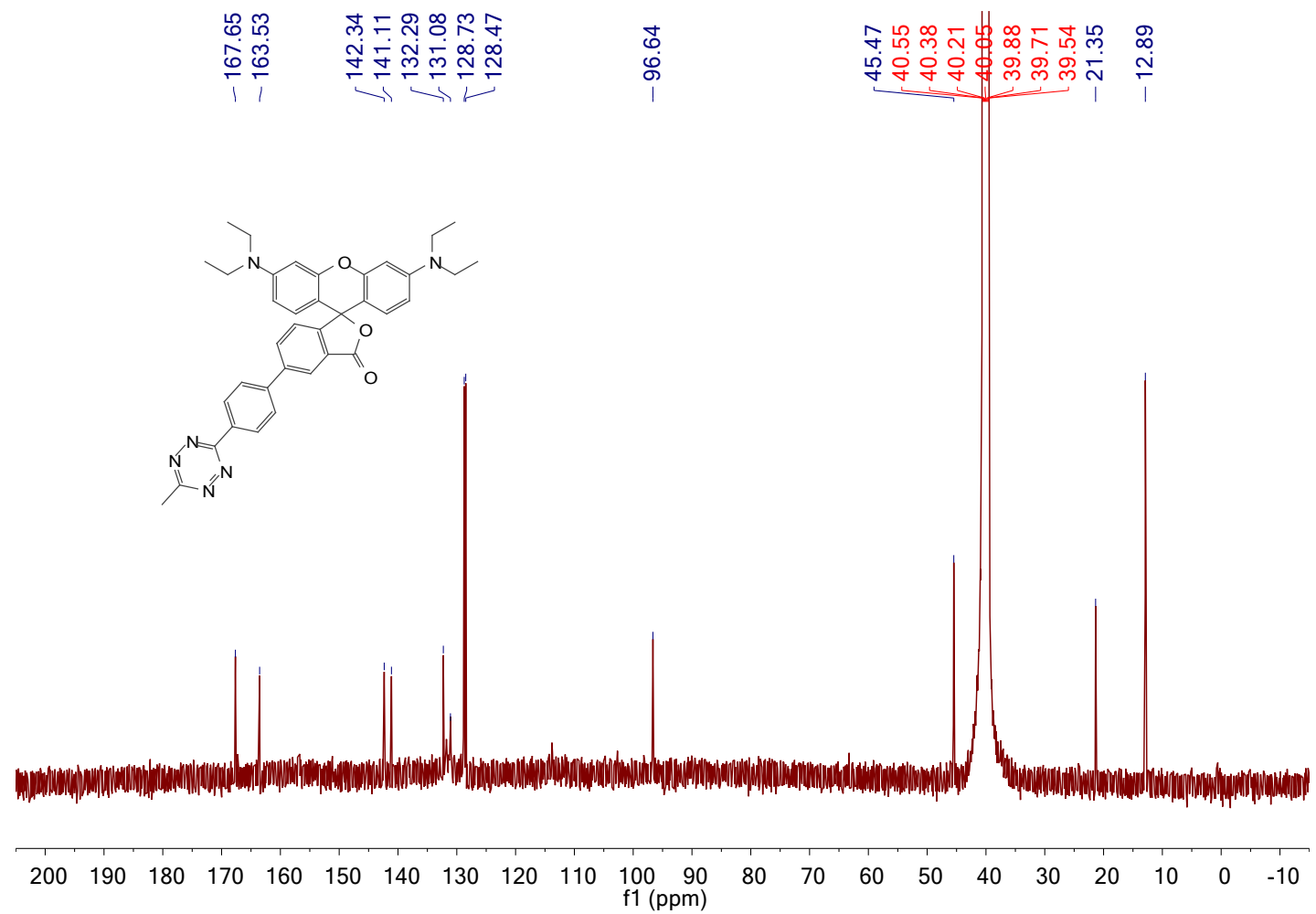

Figure S15. ${ }^{13} \mathrm{C}$ NMR spectrum of RhB-Tz 


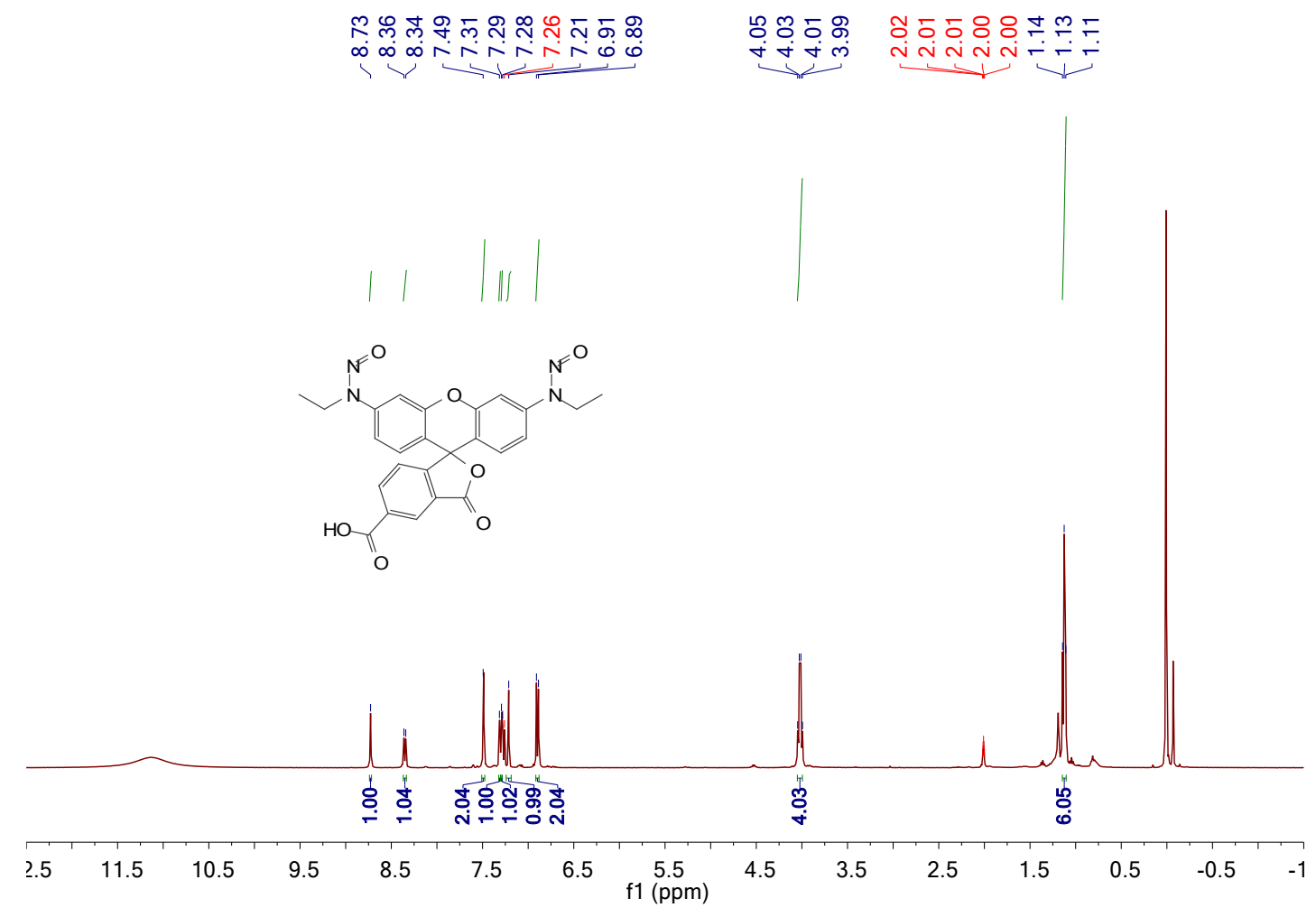

Figure S16. ${ }^{1} \mathrm{H}$ NMR spectrum of NOR-COOH

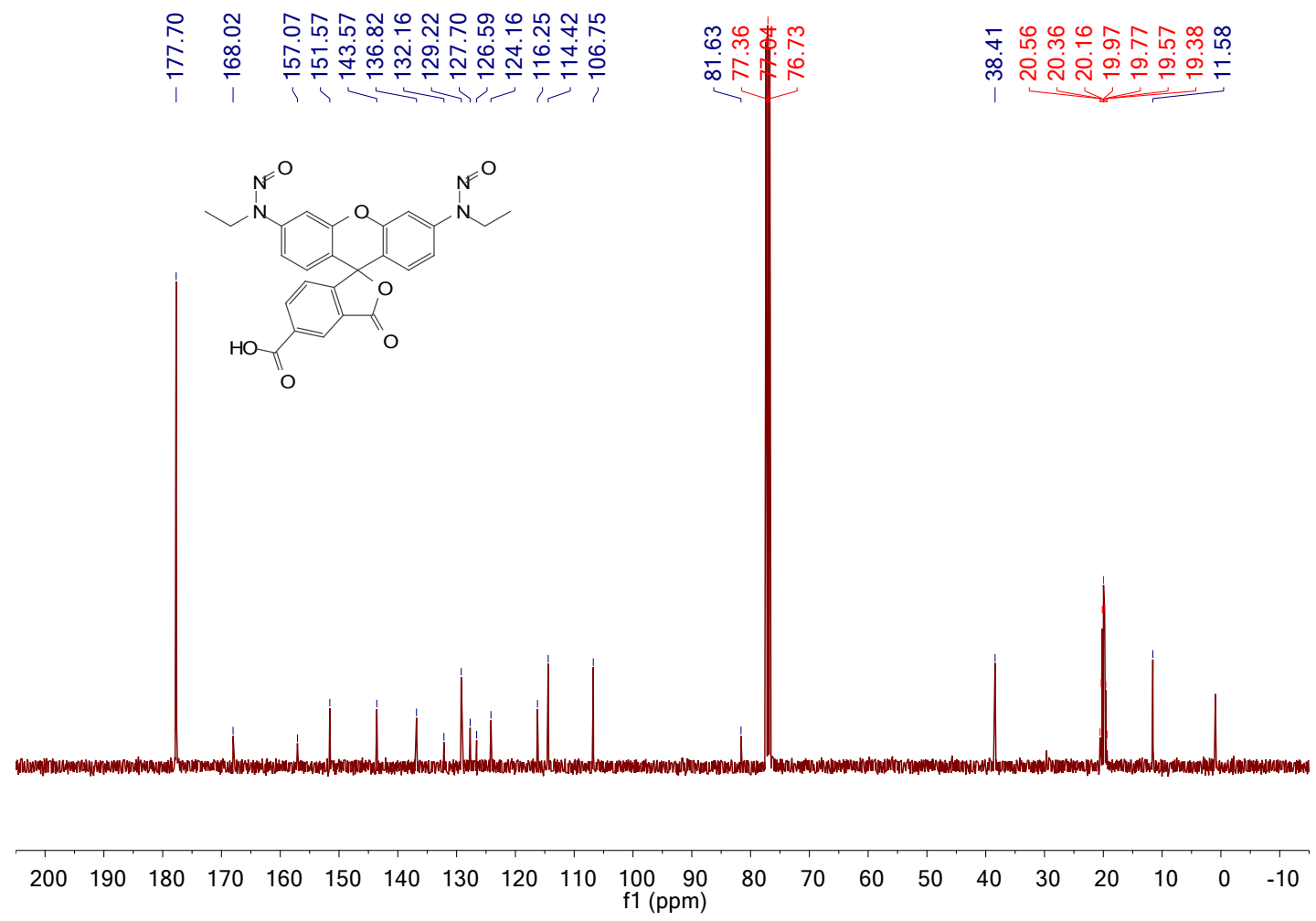

Figure S17. ${ }^{13} \mathrm{C}$ NMR spectrum of NOR-COOH 


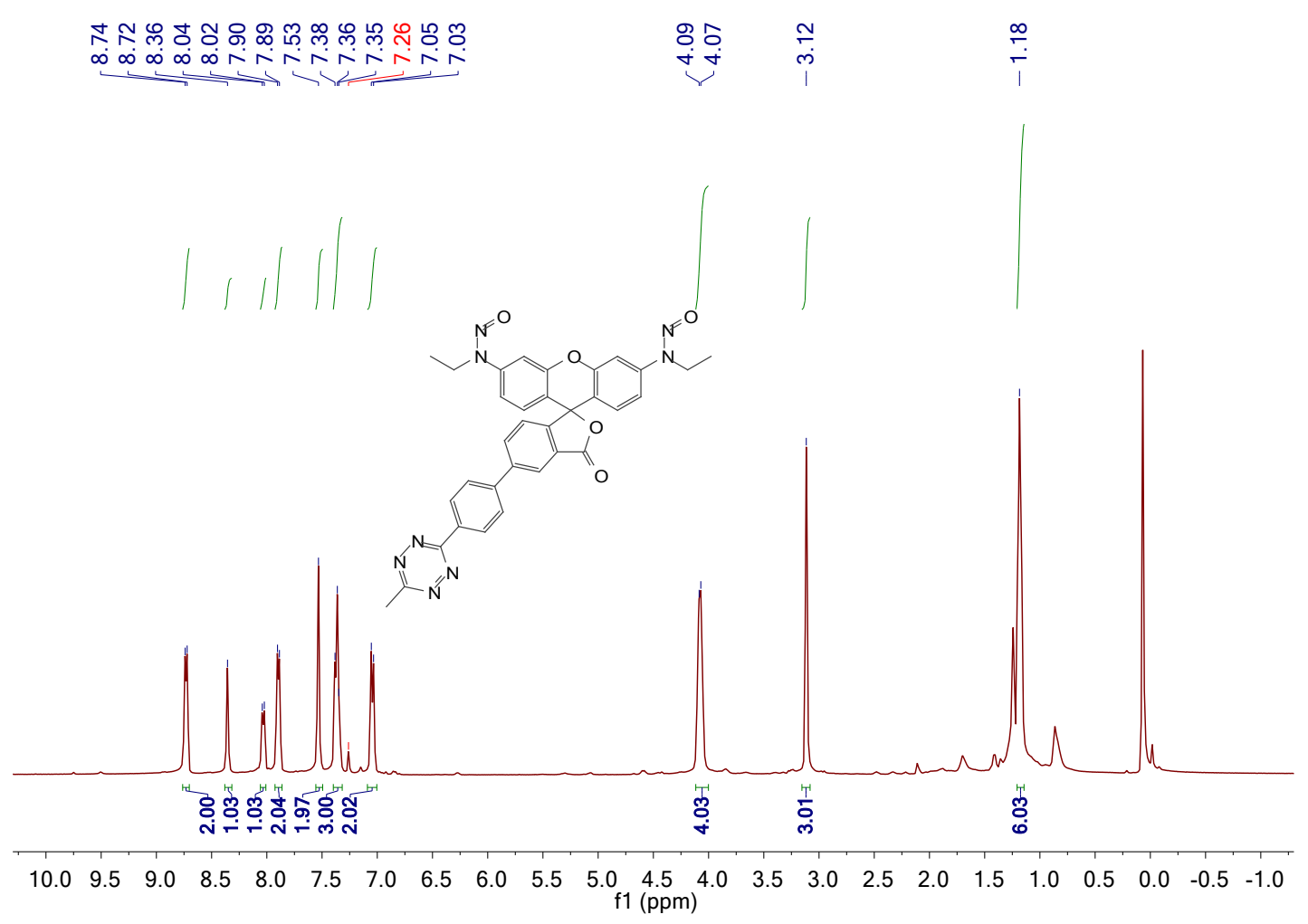

Figure S18. ${ }^{1} \mathrm{H}$ NMR spectrum of NOR-Tz

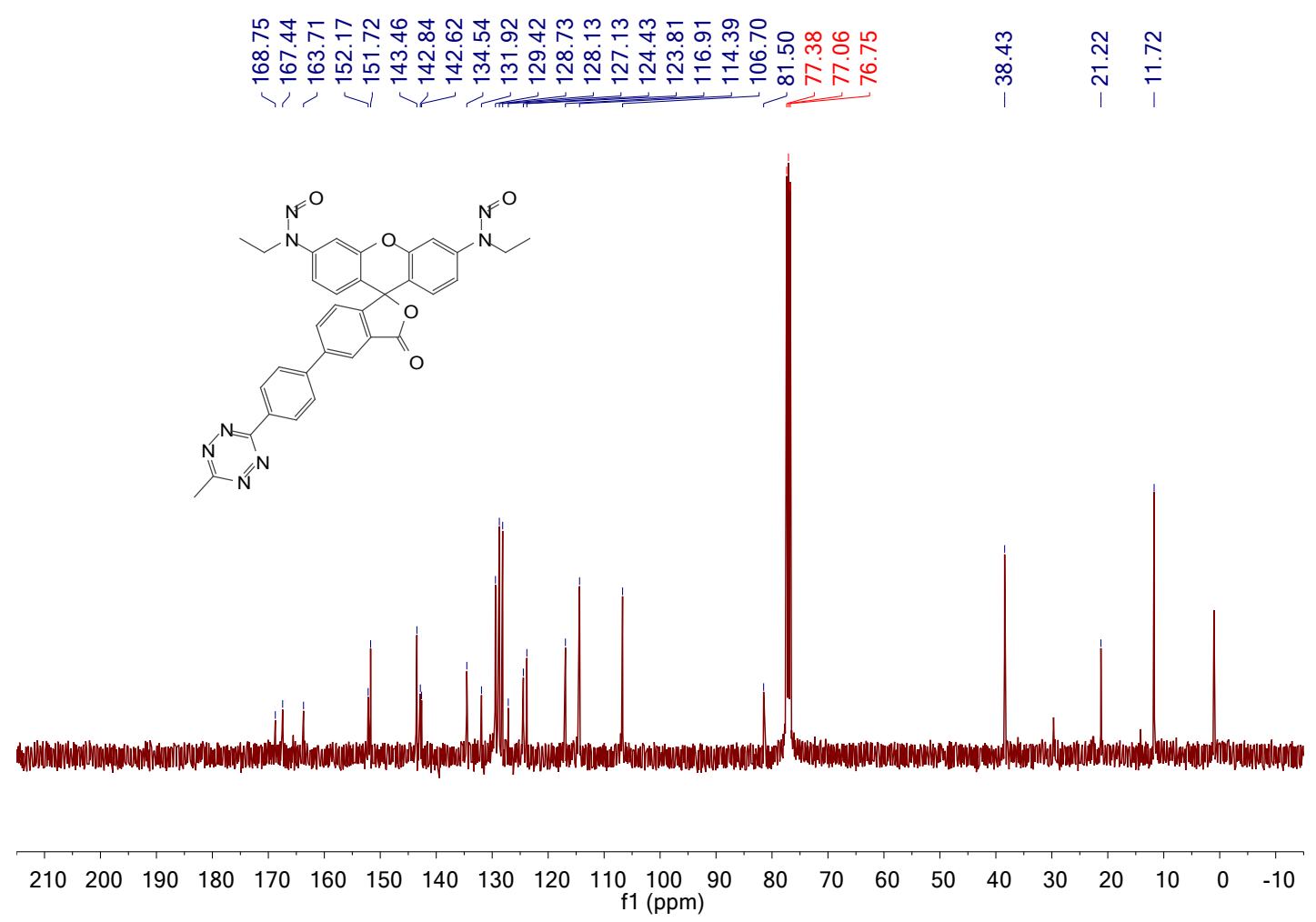

Figure S19. ${ }^{13} \mathrm{C}$ NMR spectrum of NOR-Tz 


\section{Reference}

1. Kozma, E.; Estrada Girona, G.; Paci, G.; Lemke, E. A.; Kele, P., Bioorthogonal doublefluorogenic siliconrhodamine probes for intracellular super-resolution microscopy. Chem. Commun. 2017, 53 (50), 6696-6699.

2. Li, W.; Pan, H.; He, H.; Meng, X.; Ren, Q.; Gong, P.; Jiang, X.; Liang, Z.; Liu, L.; Zheng, M.; Shao, X.; Ma, Y.; Cai, L., Bio-Orthogonal T Cell Targeting Strategy for Robustly Enhancing Cytotoxicity against Tumor Cells. Small 2019, 15 (4), 1804383.

3. Werther, P.; Yserentant, K.; Braun, F.; Kaltwasser, N.; Popp, C.; Baalmann, M.; Herten, D.-P.; Wombacher, R., Live-Cell Localization Microscopy with a Fluorogenic and Self-Blinking Tetrazine Probe. Angew. Chem. Int. Ed. 2020, 59 (2), 804-810.

4. Murrey, H. E.; Judkins, J. C.; am Ende, C. W.; Ballard, T. E.; Fang, Y.; Riccardi, K.; Di, L.; Guilmette, E. R.; Schwartz, J. W.; Fox, J. M.; Johnson, D. S., Systematic Evaluation of Bioorthogonal Reactions in Live Cells with Clickable HaloTag Ligands: Implications for Intracellular Imaging. J. Am. Chem. Soc. 2015, 137 (35), 11461-11475.

5. Marcolongo, J. P.; Schmidt, J.; Levin, N.; Slep, L. D., A chemometric approach for determining the reaction quantum yields in consecutive photochemical processes. Phys. Chem. Chem. Phys. 2017, 19 (32), 21373-21381.

6. He, H.; He, T.; Zhang, Z.; Xu, X.; Yang, H.; Qian, X.; Yang, Y., Ring-restricted N-nitrosated rhodamine as a green-light triggered, orange-emission calibrated and fast-releasing nitric oxide donor. Chin. Chem. Lett. 2018, 29 (10), 1497-1499.

7. He, H.; Xia, Y.; Qi, Y.; Wang, H.-Y.; Wang, Z.; Bao, J.; Zhang, Z.; Wu, F.-G.; Wang, H.; Chen, D.; Yang, D.; Liang, X.; Chen, J.; Zhou, S.; Liang, X.; Qian, X.; Yang, Y., A Water-Soluble, Green-Light Triggered, and Photo-Calibrated Nitric Oxide Donor for Biological Applications. Bioconjugate Chem. 2018, 29 (4), 1194-1198. 